\title{
Structure and Abrasive Wear of Composite HSS M2/WC Coating
}

\author{
S. F. Gnyusov, ${ }^{1}$ V. G. Durakov, ${ }^{2}$ and S. Yu. Tarasov ${ }^{2}$ \\ ${ }^{1}$ Tomsk Polytechnic University, 634050 Tomsk, Russia \\ ${ }^{2}$ Institute of Strength Physics and Materials Science SB RAS, 634055 Tomsk, Russia
}

Correspondence should be addressed to S. Yu. Tarasov, tsy@ispms.ru

Received 25 May 2012; Accepted 12 September 2012

Academic Editor: Huseyin Çimenoğlu

Copyright ( 2012 S. F. Gnyusov et al. This is an open access article distributed under the Creative Commons Attribution License, which permits unrestricted use, distribution, and reproduction in any medium, provided the original work is properly cited.

\begin{abstract}
Features of phase-structure formation and abrasive wear resistance of composite coatings "WC-M2 steel" worn against tungsten monocarbide have been investigated. It was established that adding $20 \mathrm{wt} \% \mathrm{WC}$ to the deposited powder mixture leads to the increase in $\mathrm{M}_{6} \mathrm{C}$ carbide content. These carbides show a multimodal size distribution consisting of $\sim 5.9 \mu \mathrm{m}$ eutectic carbides along the grain boundaries, $\sim 0.25 \mu \mathrm{m}$ carbides dispersed inside the grains. Also a greater amount of metastable austenite $(\sim 88$ vol.\%) is found. The high abrasive wear resistance of these coatings is provided by $\gamma \rightarrow \alpha^{\prime}$-martensitic transformation and multimodal size distribution of reinforcing particles.
\end{abstract}

\section{Introduction}

A tendency is to develop and build new equipment at lower costs using sparingly alloyed low carbon steels, which, however, demand surface hardening either by nitridation or carbonization. A primary task in this situation is to improve both endurance and reliability of working components of machines and technology equipment. In this connection, a solution is related not only to improving the wear resistance only but also to a totality of problems including but not limited to corrosion resistance, contact endurance, small plastic strain, and heat resistances.

Effective approach to improving the wear resistance of materials is cladding and modification metals by concentrated energy fluxes. These methods are used in practice and based on fast quenching of a melted pool at cooling rates $10^{4}$ to $10^{9} \mathrm{~K} / \mathrm{s}$. Electron beam surfacing in vacuum is a good candidate to obtain a hard coating on the surface of low carbon substrate. Such a processing provides some advantages [1] which include the ability to feed composite surfacing powders directly to the melted pool, vacuum refinement of the melted metal, gradual and accurate adjustment of the electron beam power to provide both minimal fusion penetration to the substrate, constant chemical composition, and small pool's size at electron beam power density up to $10^{5} \mathrm{~W} / \mathrm{cm}^{2}$. All these parameters may be optimized to achieve the pool's overheating required to obtain over saturated solution of the alloying elements and fine-grain structures in cooling. Taking it into account we believe that electron beam surfacing in vacuum may be applied for depositing a composite coating after final heat treatment and main mechanical grinding.

In modern practice, both hard and superhard composite coatings made of stellite, sormite, or cast tungsten carbide are used to improve wear resistance of working surfaces of machine components. A disadvantage of these materials is that they contain 30 to $90 \%$ wt. of costly tungsten carbide. Also coatings made by depositing these materials are brittle because of high hard phase content, nonuniform distribution of these particles throughout the bulk of the coating, especially for their content in the range 30 to $50 \% \mathrm{wt}$., and network cracking on the coating's surface. All of it prevents using them in a row of applications when a totality of these properties is demanded.

In particular, there is a problem of quick failure of pinion shafts of heavy loaded reduction gearboxes due to intense wear of nitrided journals in needle bearings. A design specificity of the reduction gearboxes is that their pinion shafts are positioned in close proximity to each other and traditional design of bearings consisting of external and internal rings with rollers between them is not usable. Therefore, one has to make a journal bearing directly on the pinion-shaft surface. 
These journal surfaces must possess high wear resistance, contact endurance, low plastic strains, fracture toughness, which dictates the necessity for application of homogeneous multifunctional coatings.

The specific features of coatings obtained by multipass electron beam cladding with M2 steel powder are described elsewhere [2]. It is established that a multimodal size distribution of reinforcing particles is generated in a carbide subsystem of the coating. The volume contents of both secondary carbide $\mathrm{M}_{6} \mathrm{C}$ and retained austenite can be regulated within the ranges 4.5 to $7.5 \%$ wt. and и 5 to $30 \%$ wt., respectively, as depending on the thermal cycling conditions created during the surfacing. Wear resistance of the coatings improves with the volume content of the retained austenite because of $\gamma \rightarrow \alpha^{\prime}$ strain-induced martensitic transformation and fine carbides precipitated in the matrix's grains. We can say safely that the higher is the content of the retained metastable austenite in a coating, the higher is the wear resistance. A route to go is admixing the tungsten monocarbide to the HSS powder. Since WC is of high solubility in a steel matrix, it may provide 80 to $90 \%$ vol. content of austenite as well as higher volume content of precipitated fine carbides.

Contribution of strain-induced phase transformation in abrasive wear resistance of trip steels with metastable austenite has been assessed [3] on a basis of both developed model and experimental data. Within the framework of this model the energy balance equations were derived and then served to determine the fracture work values for samples with either stable or metastable austenite. It was found out that the fracture work value for samples with metastable austenite matrix is by a factor of 7 higher as compared to that of without ability to experience strain-induced phase transformation under the same wear test conditions.

The objective of this work is to study effect of tungsten carbide content in the source mixture on the structure, phase contents, and abrasive wear resistance of HSS M2/WC composite coatings.

\section{Materials, Equipment, and Experimental Methods}

Source materials for electron beam surfacing were HSS M2 powder mixtures added with 5 to $350 \mu \mathrm{m}$ WC powder of contents 10, 15, 20, 25, 30, 40, and 50\% wt. Chemical composition of $\mathrm{M} 2$ steel was as follows: $\mathrm{C}-1 \%, \mathrm{Cr}-4 \%$, $\mathrm{W}-6.5 \%, \mathrm{Mo}-5 \%, \mathrm{~V}-1.5 \%$, Si $<0.5 \%, \mathrm{Mn}<0.55 \%$, $\mathrm{Ni}<0.4 \%, \mathrm{~S}<0.03 \%, \mathrm{O}_{2}<0.03 \%, \mathrm{Fe}$-balance. Composite mixtures were prepared by mixing the above components, compacting and sintering the mixtures in vacuum at partial pressure not higher $10^{-2} \mathrm{~Pa}$, followed by milling and sieving the cakes by fractions. Surfacing was carried out on flat $20 \times$ $30 \times 200 \mathrm{~mm}$ samples of $0.3 \% \mathrm{C}$ steel by applying four passes per each plate. The scanning-line length was $20 \mathrm{~mm}$. The thickness of clad metal layer per pass was $1 \mathrm{~mm}$. Some samples were subjected to either single or double tempering carried out at $570 \pm{ }^{\circ} \mathrm{C}$ for 1 hour.

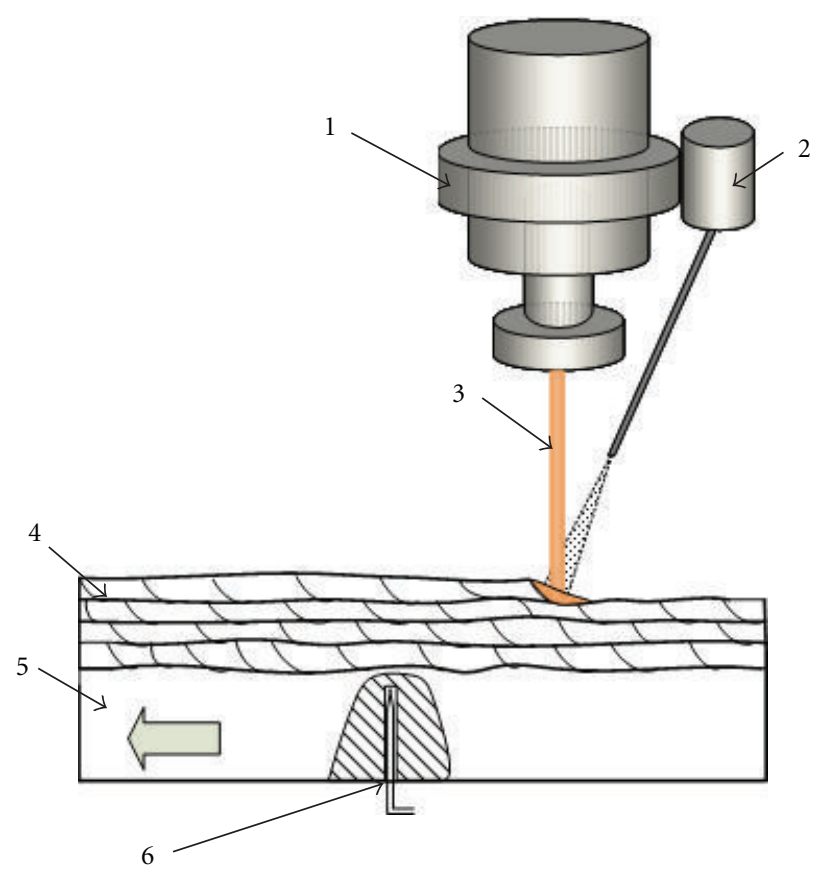

FIGURE 1: Schematic of the electron beam surfacing. 1: electron gun; 2: powder feeder; 3: electron beam; 4: coating; 5: substrate; 6: thermocouple.

A machine for electron beam cladding in vacuum was operated in automatic mode so that samples were loaded into its chamber and secured there in manipulators. These manipulators are driven in rotation and displacement modes by external electrodrive system. The chamber was evacuated to reach the residual pressure $10^{-1} \mathrm{~Pa}$. Electron beam generated by the electron gun was scanned over the surface of the sample thus creating a melted pool (Figure 1). Simultaneously, the powder mixture was fed to the pool by means of a measure feeder.

Accelerating voltage, diameter, electron beam sweep length, and sample feed velocity were $28 \mathrm{kV}, 1 \mathrm{~mm}$, and $20 \mathrm{~mm}, 2 \mathrm{~mm} / \mathrm{s}$, respectively, and did not change during the experiment.

The microstructure of the deposited coatings in the longitudinal and transverse microsections was examined using optical microscope (OM) Olympus GX 51 equipped with 700 SIAMS analysis device, SEM instrument Philips SEM 515 equipped with microanalysis device EDAX ECON IV, and TEM Tecnai G2 FEI instrument equipped with a microanalysis device.

Traditional method of preparing the microsections such as mechanical grinding and polishing with diamond pastes of different grades was used in this work. Chemical etching was performed in $4 \%$ solution of $\mathrm{HNO}_{3}$ in alcohol. Determining the quantitative characteristics of the microstructure including number, size, shape, and distribution of various phases was performed using the SIAMS software package. TEM foils of thickness $150 \mu \mathrm{m}$ were cut from coatings using an electrospark machine. After mechanical and electrolytic finishing, 
to achieve the foils' thicknesses 70 to $90 \mu \mathrm{m}$, the final ion thinning was carried out to achieve $200 \mathrm{~nm}$ thickness.

Phase composition of the samples both after surfacing and abrasion wear tests was investigated by XRD using Shimadzu XRD 6000 diffractometer operated in the $2 \Theta$ range 30 to 120 degrees at $0.02^{\circ}$ step and with filtered $\operatorname{CoK} \alpha$ radiation. Integrated intensities of the diffraction peaks were used for the quantitative phase analysis. The volume content of a phase in a multicomponent system was determined according to an expression as follows:

$$
\begin{gathered}
V_{\alpha}=\frac{K_{\alpha}\left(I_{\alpha} / I_{\beta}\right)}{1+K_{\alpha}\left(I_{\alpha} / I_{\beta}\right)+K_{\gamma}\left(I_{\gamma} / I_{\beta}\right)+K_{\varepsilon}\left(I_{\varepsilon} / I_{\beta}\right)+\cdots}, \\
K_{\alpha}=\frac{Q_{\alpha}^{2}\left(P \Phi F^{2}\right)_{\beta}}{Q_{\beta}^{2}\left(P \Phi F^{2}\right)_{\alpha}},
\end{gathered}
$$

where $\alpha, \beta, \gamma$, and $\varepsilon$ stand for phases, $\Phi$ is the angle factor, $P$ is the multiplicity factor, and $F$ and $Q$ are the phase's structural factor and cell volume, respectively.

2.1. Microhardess and Wear. Microhardness numbers $\left(H_{\mu}\right)$ of both the coating and the substrate were measured using PMT-3 microhardness tester operating at $100 \mu \mathrm{m}$ step between the indents and load of $0.981 \mathrm{~N}$. The measurements were carried out on two parallel indentation paths shifted by $50 \mu \mathrm{m}$ in depth with respect to each other. The distance between the paths was $200 \mu \mathrm{m}$. Such a procedure allowed obtaining the microhardness in-depth profiles of $50 \mu \mathrm{m}$ step in the coating.

To determine the wear rate ( $\mathrm{mg} /$ hour) we used method of loose abrasive particles (Figure 2) and measured the mass losses hourly. The mean wear rate was then calculated from five experimental results. Faceted quartz sand particles with sharp corners and edges and round electrocorundum particles of mean size $d_{m}=100$ to $300 \mu \mathrm{m}$ were used as abrasive material for wear testing at 60 RPM. Normal load was $44.1 \pm$ $0.25 \mathrm{~N}$. The analysis of microstructure and microhardness of the specimens after wear tests was performed on taper sections made at $2^{\circ}$ angle between the top surface and the section plane.

The analysis of microstructure and microhardness of the specimens after wear tests was performed on taper sections made at $2^{\circ}$ angle between the top surface and the section plane.

\section{Results and Discussion}

HSS M2 + WC mixtures of WC contents 10, 15, 20, 25, 30, 40 , and $50 \% \mathrm{wt}$. were prepared by ball milling for 24 hours. Sintering the mixtures was carried out in a vacuum oven at $1200^{\circ} \mathrm{C}$ for 1 hour. If using the lower temperatures, the particles do not sinter one to each other and no quality composite cakes are obtained. At temperatures above $1200^{\circ} \mathrm{C}$ the cakes are very hard to mill and the powder yield is too low. The resulting cakes were milled and sieved to particle size fractions. The yield of usable milled composite 30 to $350 \mu \mathrm{m}$

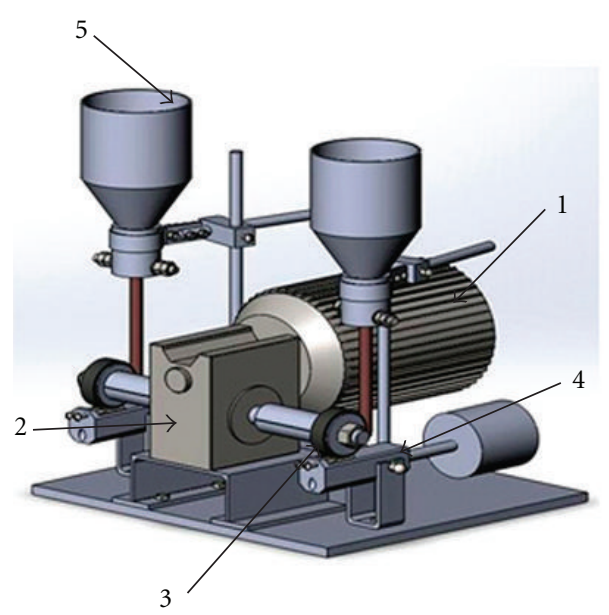

Figure 2: Schematic of abrasive wear test setup. 1: electromotor; 2: worm gear; 3: rubber counterbody; 4: tested sample.

fraction was 85 to $90 \%$. The smaller particle fractions were discarded.

The microstructure of a composite cake intended for surfacing is shown in Figure 3. As seen, the isolated particles of M2 steel are surrounded either by islet shape phase (a) only or angular 1 to $2 \mu \mathrm{m}$ particles in combination with the islets (b) as depending on the WC content in the mixture. Increasing the source WC content from 10 to $40 \%$ wt. results in increasing the amount of angular particles from 0 to 20 $25 \%$ vol. in the cake.

According to XRD (Figure 4), two carbides such as WC and $\mathrm{M}_{6} \mathrm{C}$ were found in the cakes in addition to the matrix's phases $\alpha$ and $\gamma$. It means that the source powder particles interact with each other in the course of sintering to produce a composite. That such is true is supported by the results reported elsewhere [4]. The authors [4] show that $\mathrm{M}_{6} \mathrm{C}$ carbide's formation starts after heating the composite WC-(Ni$\mathrm{Al}$ ) and WC-NiTi mixtures to $700^{\circ} \mathrm{C}$. Taking into account the morphology, we can state that $\alpha$-phase found in cakes is in the form of martensite needles.

Examining the microstructures as well as the XRD data obtained from the surfaced samples (Figure 4), we can see that coatings are composed of $\alpha$-martensite, retained austenite ( $\gamma$-phase), 0.9 vol. $\%$ of $d_{1}=0.65 \mu \mathrm{m}$ VC carbides, and $\mathrm{M}_{6} \mathrm{C}$ carbide (Figure 5). This $\mathrm{M}_{6} \mathrm{C}$ carbide is of two morphological types. The first type I is presented by dendritelike eutectic $3.8 \mu \mathrm{m}$ carbides (Figures 5(a) and 5(b)) found at the grain boundaries of solid solution. Second type II carbides look like fine elongated particles inside the grains (Figure $5(\mathrm{~d})$ ). Table 1 shows the data on chemical composition of structures detected in the points shown in Figures 5(c) and 5(d). The data in Table 1 allow conclusion on essential reduction in the vanadium content of secondary $\mathrm{M}_{6} \mathrm{C}$ carbides as compared to that of the eutectic carbides.

On admixing more tungsten carbide to the source mixture, the amount of $\mathrm{M}_{6} \mathrm{C}$ carbides grows (Figure 6(a)) and starting from WC $30 \% \mathrm{wt}$. and higher some amount of the source WC retained in addition to the above shown. 
TABLE 1: Chemical composition of carbides found in composite coatings.

\begin{tabular}{|c|c|c|c|c|c|c|c|}
\hline \multirow{2}{*}{ No. point } & \multirow{2}{*}{ Phase } & \multicolumn{6}{|c|}{ Chemical composition, \% wt. } \\
\hline & & $\mathrm{C}$ & $\mathrm{V}$ & $\mathrm{Cr}$ & $\mathrm{Fe}$ & $\mathrm{W}$ & Mo \\
\hline 1 & $\mathrm{M}_{6} \mathrm{C}$ (eutectic) & 5.0 & 27.0 & 2.8 & 2.3 & 44.6 & 18.3 \\
\hline 2 & $\mathrm{M}_{6} \mathrm{C}$ (secondary) & 1.6 & 7.0 & 6.1 & 5.1 & 54.9 & 25.3 \\
\hline 3 & $\mathrm{M}_{6} \mathrm{C}$ (secondary) & 1.8 & 6.6 & 5.4 & 5.3 & 55.1 & 25.8 \\
\hline 4 & Matrix & 1.8 & 1.1 & 3.0 & 77.4 & 10.8 & 5.9 \\
\hline 5 & Matrix & 2.2 & 0.9 & 2.9 & 77.2 & 10.2 & 6.5 \\
\hline
\end{tabular}

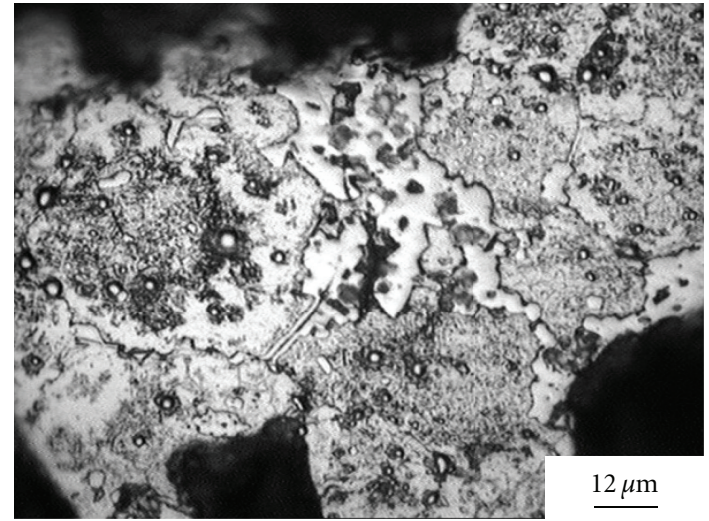

(a)

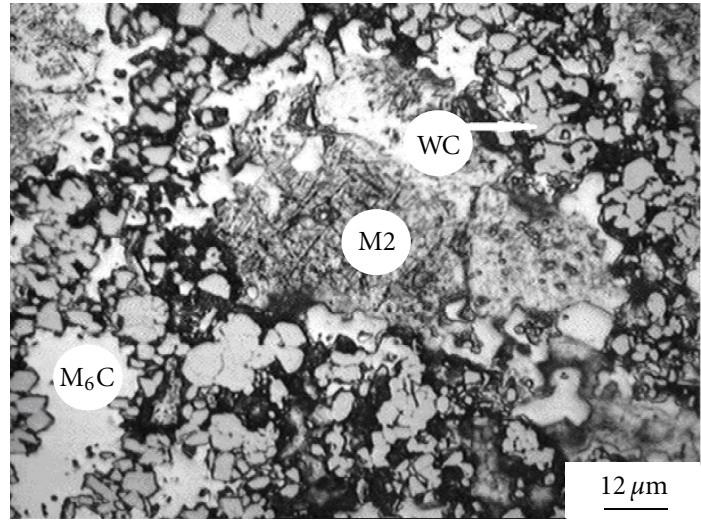

(b)

FIGURE 3: The postsintering microstructure of composite HSS M2 + WC intended for electron beam surfacing. (a) WC 20\% wt.; (b) WC $40 \%$ wt.

(Figures 6(b) and 6(c)). $\mathrm{M}_{6} \mathrm{C}$ carbide in coatings obtained using mixtures of WC content below 30\% wt. was found in the form of dendrite-like precipitations at the austenite grain boundaries having a mean size $d_{2}=5.9 \mu \mathrm{m}$ and content $\sim 15$ vol. \%. In addition to that, it exists in the form of fine $d_{3}=0.24 \mu \mathrm{m}$ precipitations inside the austenitic grains of total content $\sim 8 \%$ vol. It is made clear that electron beam cladding composite coatings with up to $30 \% \mathrm{wt}$. WC may result in generation of a multimodal size distribution of hard phase carbide particles in the coating.

Coarse faceted particles of $\mathrm{M}_{6} \mathrm{C}$ carbide were found in coatings obtained from the source powder mixtures of WC content $40 \%$ wt. (Figure 6(c)). These particles grow even larger when the WC content grows up to $50 \%$ wt. (Figure 6(d)). Furthermore, it exists in two morphological types such as globular and elongated (platelets) particles. These coarse mixed carbide particles form a developed framework. The retained WC particles are surrounded by $\mathrm{M}_{6} \mathrm{C}$ precipitations and built in the framework. Binder phase was found in the form of isolated particles. It is inconceivable to suggest that such a framework structure of the reinforcing phase will hardly serve to improve the wear resistance. The coarse carbides will plausibly have positive effect on abrasive wear resistance. The wear resistance of a framework built of fine $\mathrm{M}_{6} \mathrm{C}$ carbides will be determined by the phase composition of the matrix.

The dependence of the austenite's amount on the tungsten carbide's content in the source powder is a curve with a maximum in the range 20 to $25 \%$ wt. of WC (Figure $7(\mathrm{a})$ ).
Both single and double tempering the deposited coating result in partial $\gamma \rightarrow \alpha$ martensitic transformation. It is established that electron beam surfacing with deposition of both pure M2 steel powder and M2 + WC 40 to 50\% wt. mixtures gives only 3 to $4 \%$ vol. of retained austenite. However, if we used M2 + WC 20 to 30\% wt. mixtures, the composite coatings contained 30 to $40 \%$ vol. of retained austenite even after conducting the double tempering.

It is notable that the coatings made using $\mathrm{M} 2+\mathrm{WC} 0$ to $30 \% \mathrm{wt}$. showed no network cracking on their surfaces.

The ascending part of the curve in Figure 7(a) shows the amount of the retained austenite increasing up to $82 \%$ vol. with adding 20 to $25 \%$ WC wt. to the source powder mixture. Such an effect is provided by better solubility of WC and, therefore, the greater effect of alloying the $\gamma$-solid solution both by carbon and carbide-forming elements.

According to the EDAX data, the solubility of tungsten in the coating's matrix grows from 3.5 to $11 \%$ wt. with the WC content in the source mixture. This involves reducing the onset temperature of martensitic transformation and increasing the amount of metastable retained austenite after cooling (quenching). It follows from $[5,6]$ that, increasing the temperature of quenching for HSS M2, we simultaneously increase the content of both carbon and alloying elements, which reduce the martensitic transformation point. In our situation, we actually deal with quenching from a liquid micropool that serves to additionally reduce the martensitic transformation temperature interval. The higher content of retained austenite provides for minimal hardness 


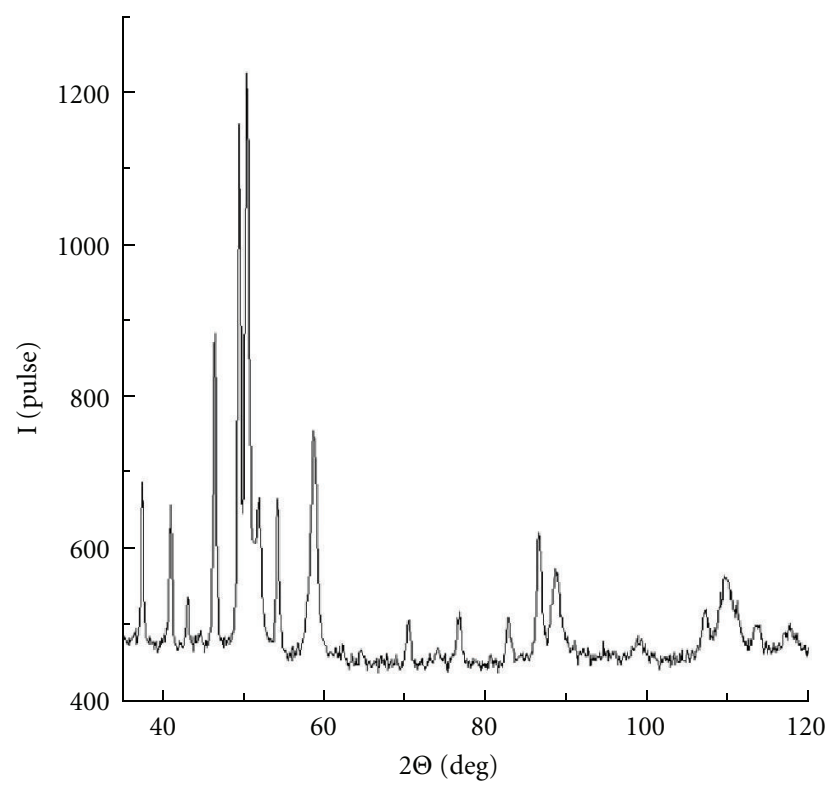

\begin{tabular}{|c|c|c|c|}
\hline No. & $2 \Theta(\operatorname{deg})$ & $\mathrm{d}(\mathrm{nm})$ & Phase \\
\hline 1 & 37.734 & 0.27660 & $\mathrm{M}_{6} \mathrm{C}(400)$ \\
\hline 2 & 41.265 & 0.25384 & $\mathrm{M}_{6} \mathrm{C}(331)$ \\
\hline 3 & 43.343 & 0.24222 & $\mathrm{VC}(111)$ \\
\hline 4 & 46.682 & 0.22576 & $\mathrm{M}_{6} \mathrm{C}(422)$ \\
\hline 5 & 49.684 & 0.21291 & $\mathrm{M}_{6} \mathrm{C}(511)$ \\
\hline 6 & 50.652 & 0.20910 & $\gamma$-Fe (111), VC (200) \\
\hline 7 & 52.008 & 0.20401 & $\alpha-\mathrm{Fe}(110)$ \\
\hline 8 & 54.435 & 0.19557 & $\mathrm{M}_{6} \mathrm{C}(440)$ \\
\hline 9 & 58.870 & 0.18201 & $\gamma$-Fe (200) \\
\hline 10 & 70.556 & 0.15487 & $\mathrm{M}_{6} \mathrm{C}(551)$ \\
\hline 11 & 76.777 & 0.14404 & $\alpha-\mathrm{Fe}(200), \mathrm{M}_{6} \mathrm{C}(553)$ \\
\hline 12 & 82.821 & 0.13523 & $\mathrm{M}_{6} \mathrm{C}(733)$ \\
\hline 13 & 86.655 & 0.13036 & $\mathrm{M}_{6} \mathrm{C} \quad(822)$ \\
\hline 14 & 88.747 & 0.12790 & $\gamma-\mathrm{Fe}(220), \mathrm{M}_{6} \mathrm{C}(555)$ \\
\hline 15 & 98.808 & 0.11780 & $\alpha-\mathrm{Fe}(211)$ \\
\hline 16 & 107.139 & 0.11117 & $\mathrm{M}_{6} \mathrm{C}(933)$ \\
\hline 17 & 109.682 & 0.10941 & $\gamma$-Fe (311) \\
\hline 18 & 111.162 & 0.10843 & $\mathrm{M}_{6} \mathrm{C}(862)$ \\
\hline 19 & 113.484 & 0.10697 & $\mathrm{M}_{6} \mathrm{C}(733)$ \\
\hline 20 & 116.984 & 0.10491 & $\alpha-\mathrm{Fe}(220)$ \\
\hline 21 & 117.652 & 0.10454 & $\gamma$-Fe (222) \\
\hline
\end{tabular}

FIgURE 4: XRD data for composite coating M2 + 20\% wt. WC.

of M2 + 20\% wt. WC composite coatings being at the level of $6 \mathrm{GPa}$ (Figure 7(b), curve 1).

As seen from the descending part of curve in Figure 7(a), the amount of retained austenite is reduced when the WC content in the source mixture grows from 30 to $50 \%$ wt. The rationale behind that is incomplete dissolution of both $\mathrm{M}_{6} \mathrm{C}$ and WC particles, which then serve either as crystallization nuclei or substrates for epitaxial growth of mixed carbide from austenite. Simultaneously, the same effect reduces the overheating of the melted pool as well as, consequently, the solubility of carbides in it. Moreover, the reduced content of a binder phase in the coating facilitates relaxation of stress generated by the difference in phase volumes of $\alpha$ and $\gamma$ phases. Also this serves for more full $\gamma \rightarrow \alpha$ transformation. The discussed here abnormal behavior of austenite in coatings must have effect on their wear resistance.

3.1. Abrasive Wear. The wear rate by quartz particles is reduced quickly for hard coatings containing up to $20 \%$ wt. 


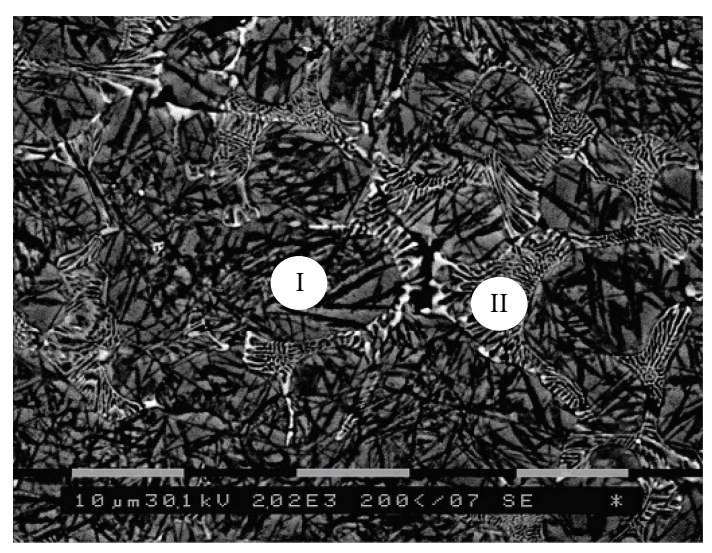

(a)

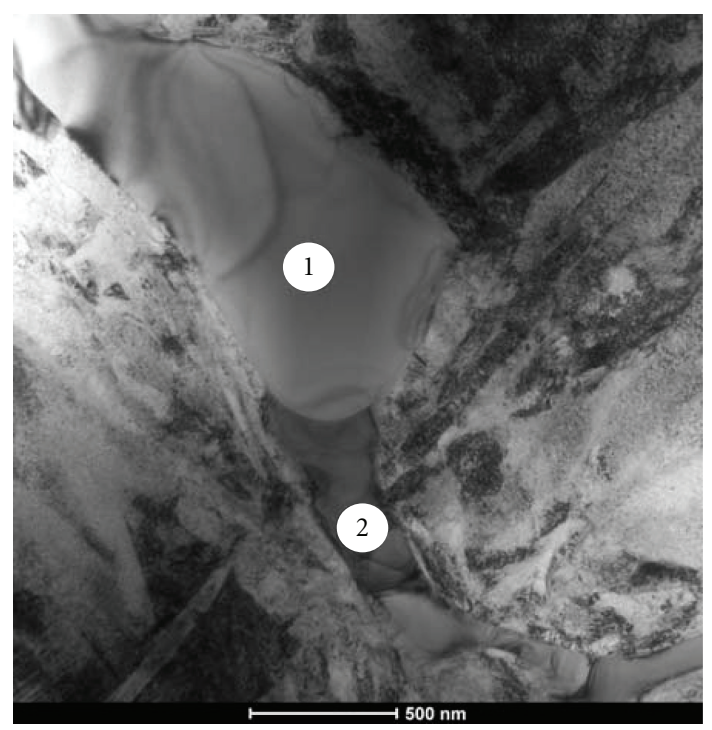

(c)

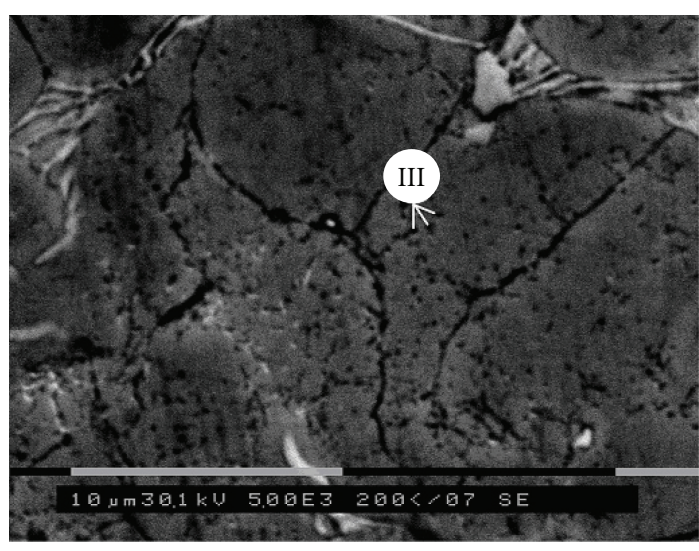

(b)

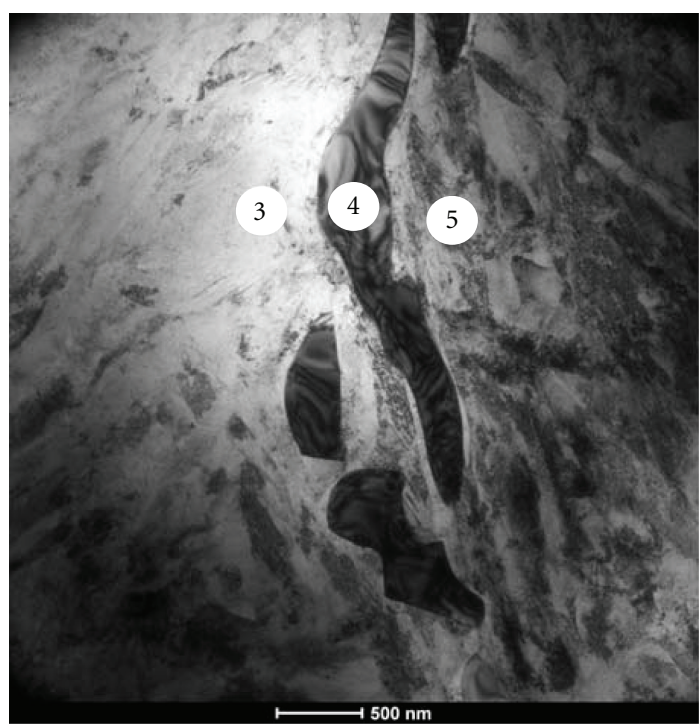

(d)

FIgURE 5: The microstructure of M2 coating clad on the substrates. ((a), (b) SEM, (c), (d) TEM).

WC whereas some growth is observed for 25 to $30 \%$ wt. WC coatings. However, the wear rate continues falling for higher WC content (Figure 8(a)). The local wear rate maximum (Figure 8(a)) may find its explanation in structural changes occurring in the coating when depositing $20 \%$ wt. WC powder mixtures. In this case, a carbide framework structure starts forming involving source WC particles. Also the use of faceted shape of abrasive quartz particles may add to this effect. When using electrocorundum, the wear rate is reduced with the WC content growth. This is especially the case for coatings deposited from $20 \% \mathrm{wt}$. WC powder mixtures (Figure 8(b)). Another aspect is that using more hard abrasive particles provides higher wear rate by a factor of $\sim 20$ as compared to quartz sand.

Taking into account the microstructures in Figures 5 and 6, volume content of austenite in Figure 7(a), hardness (Figure $7(\mathrm{~b})$ ), and wear rate dependencies in Figure 8 as functions of WC content in the source powder mixture, we can say that the wear resistance is improved due to higher amount of austenite in samples surfaced to obtain the multimodal $\left(d_{1}, d_{2}\right.$, and $\left.d_{3}\right)$ size distribution of hardening carbide phases. Such a distribution serves to provide thinner intercarbide binder layers and, thus, to reduce their selective wear and prevent carbides from spalling.

Also since the metastable austenite is capable of partial strain-induced martensitic $\gamma \rightarrow \alpha^{\prime}$ transformation, this provides for extra stress relieve effect during wear. In accordance to XRD data, the amount of $\alpha^{\prime}$-phase in M $2+20 \%$ WC coating has grown by $40 \%$ vol. after abrasive wear test. This martensitic transformation in combination with substructural work hardening results in growth of hardness from 6 to $10 \mathrm{GPa}$ in the subsurface of coatings at $40 \mu \mathrm{m}$ depth below the worn surface (Figure 7(b)).

Another structural factor important for improving the wear resistance of composite coating with metastable austenite matrix is its higher ability to hold brittle carbide phases as compared to martensite and, thus, prevent them against spalling both in microcutting and fatigue wear. This is true both for primary dendrite carbides found at the grain boundaries and secondary equiaxed intragrain fine carbides [4]. Neither single nor double tempering the coatings is able to change the dependence of wear rate on the tungsten carbide 


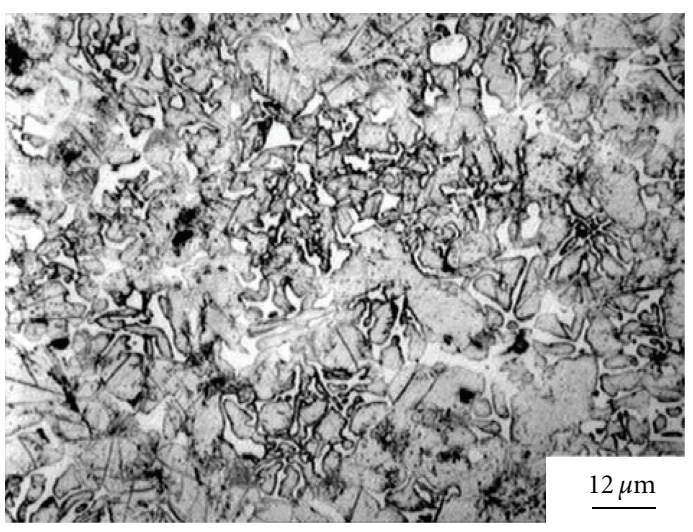

(a)

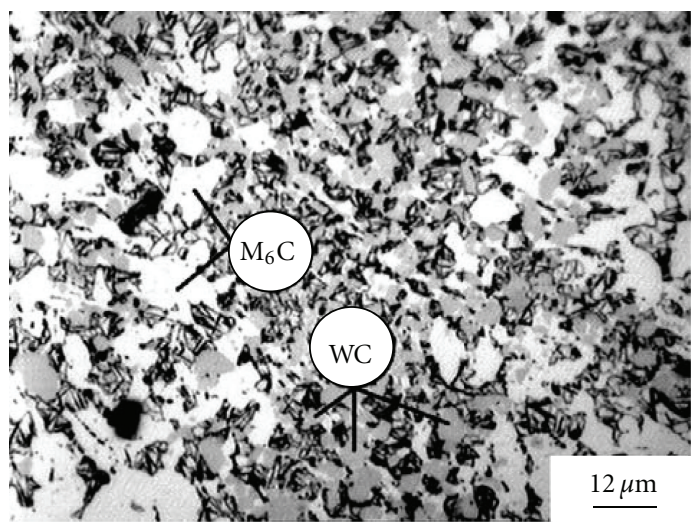

(c)

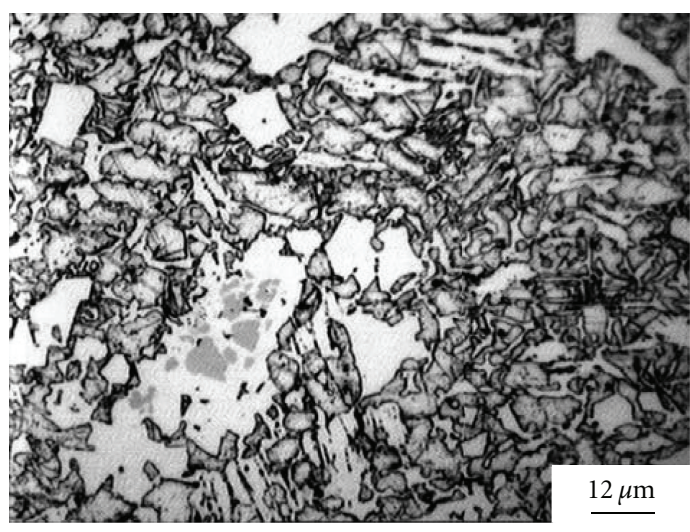

(b)

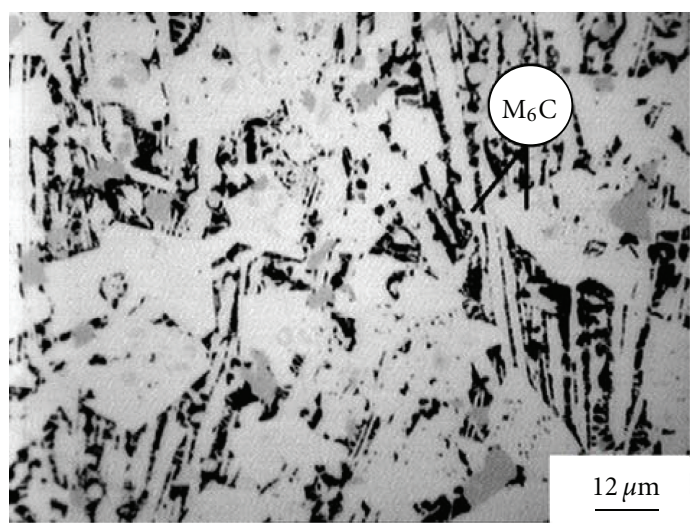

(d)

Figure 6: The microstructure of composite coating clad on the substrates; (a) "M2 + 20\% WC"; (b) "M2 + 30\% wt. WC"; (c) "M2 + 40\% wt. WC"; (d) "M2 + 50\% wt. WC".

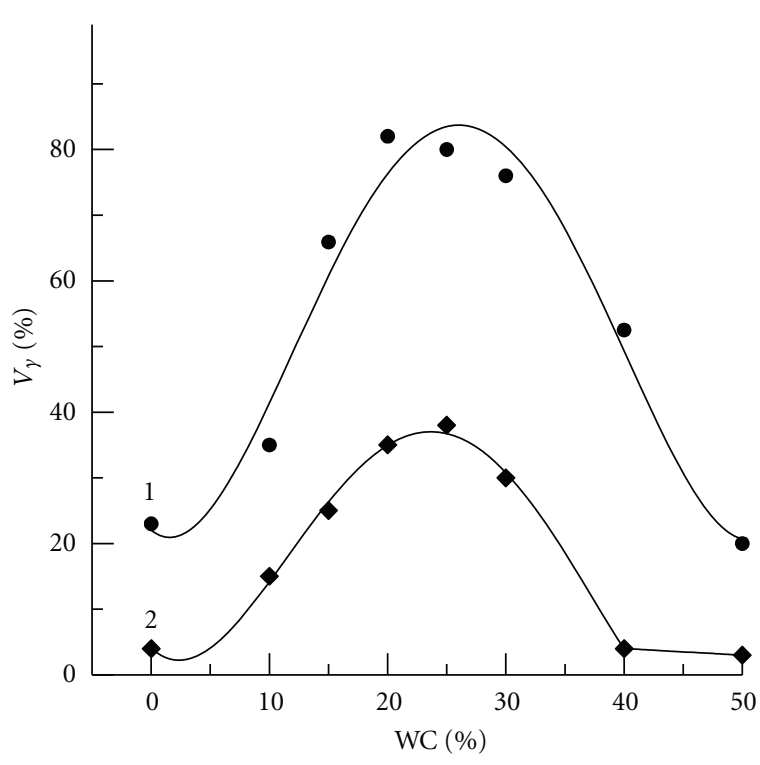

(a)

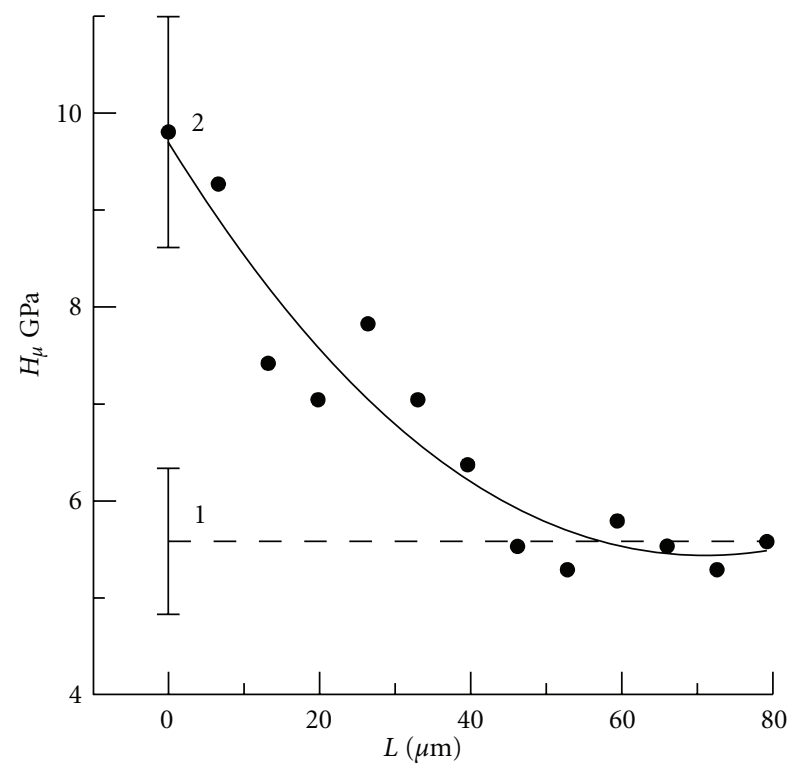

(b)

FIGURE 7: Volume content of austenite in the coating's matrix versus WC content in the source powder mixture (a), curve 1 is for deposited coating, curve 2 is for double tempering, and microhardess numbers as a function of depth below the worn surface for the coating made using M2-20 wt.\% WC mixture. ((b), curve 2) 1: initial microhardness. 


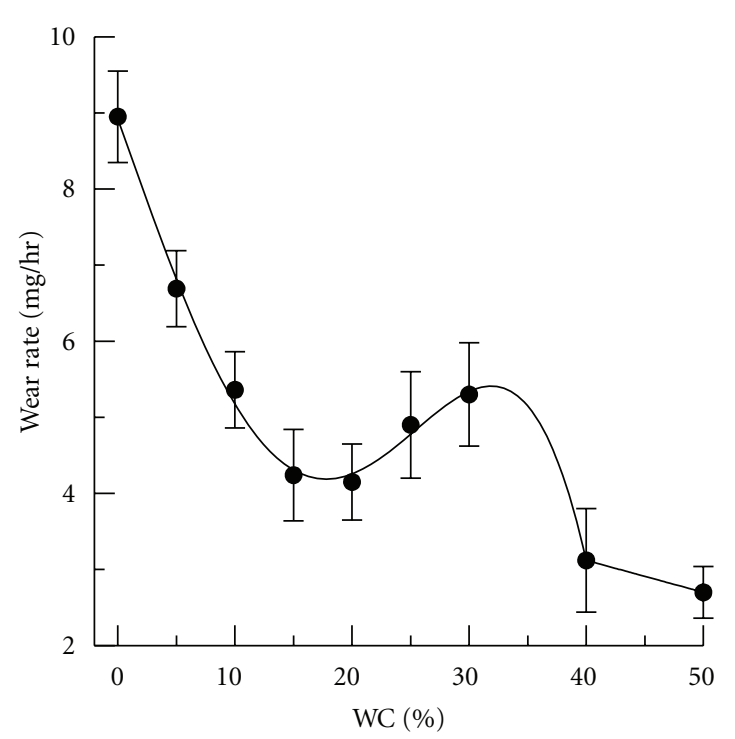

(a)

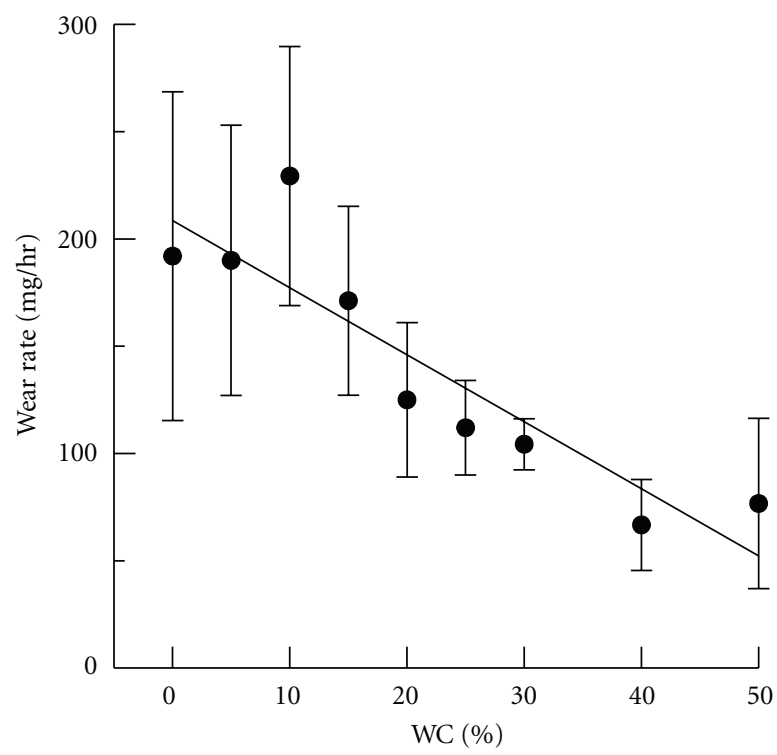

(c)

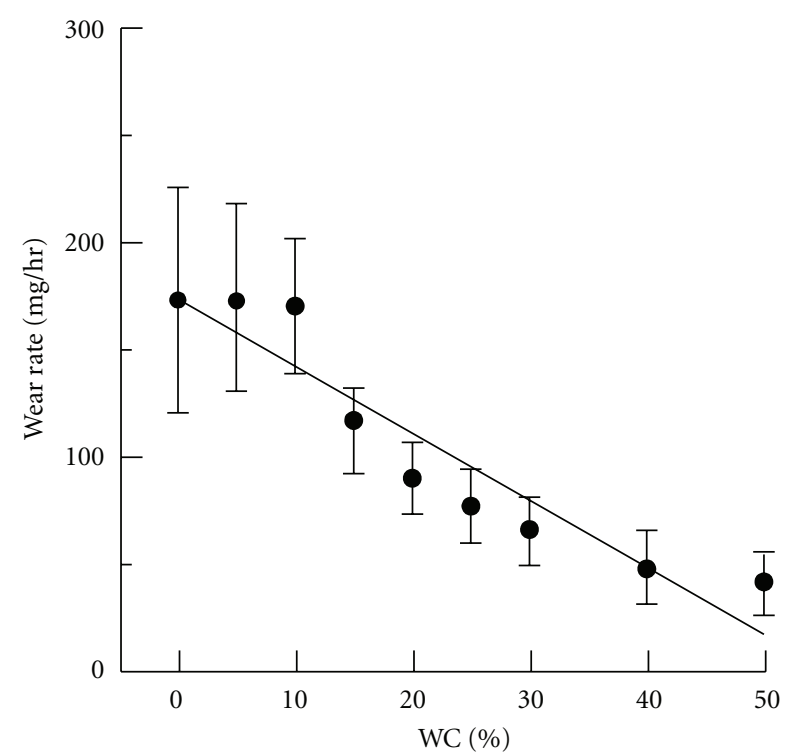

(b)

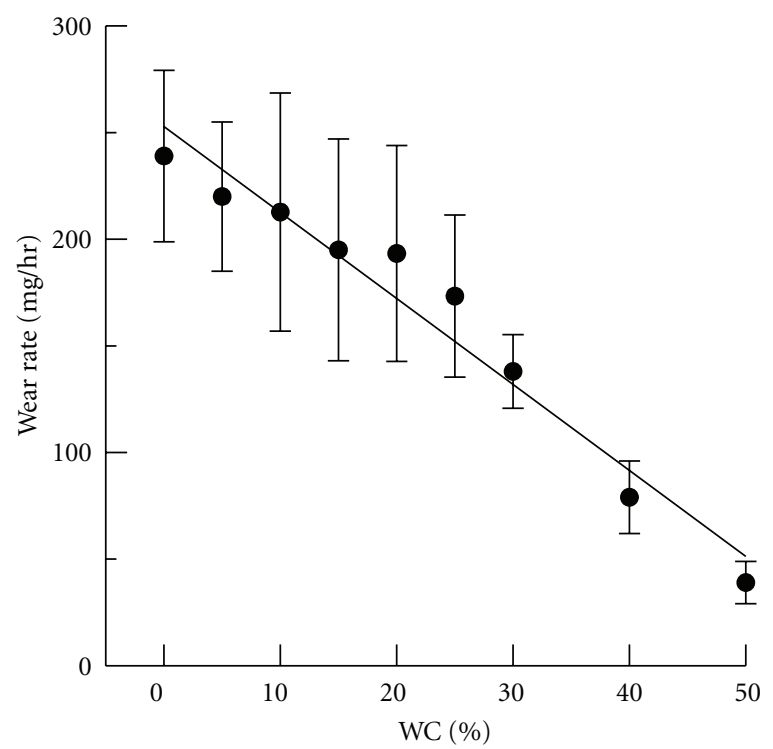

(d)

FIGURE 8: Abrasive wear rate versus WC content in the source powder mixture. (a) Quartz sand, ((b), (c), (d)) electrocorundum; (a), (b) just after cladding; (c) single tempering; (d) double tempering.

content albeit the absolute values are somewhat increased as compared to those after surfacing (Figures $8(\mathrm{~b}), 8(\mathrm{c})$, and $8(\mathrm{~d}))$. Such a behavior may be related to the fact that tempering partially transforms austenite to martensite and, therefore, reduces the effect of austenite for relieving stresses in $\gamma \rightarrow \alpha^{\prime}$ transformation. From this standpoint, tempering is not a heat treatment desired after surfacing.

The wear rate of $\mathrm{M} 2+40 \%$ wt. WC coating is greatly influenced by the heat treatment. The microstructure of this coating reveals a carbide framework composed of $\mathrm{M}_{6} \mathrm{C}$ and WC carbides (Figure 6(c)). The binder of a just sur-faced coating contains about $50 \%$ vol. of austenite (Figure $7(\mathrm{a})$ ), which has positive effect both on stress relieving and preventing spalling of the carbide particles.
Since tempering results in partial $\gamma \rightarrow \alpha^{\prime}$ transformation, it serves to impair both resistance to spalling and carbide retention ability. Finally, the wear rate of $\mathrm{M} 2+40 \%$ wt. WC coatings is increased by $40 \%$ for wear by electrocorundum particles.

The carbide framework formation is observed in $\mathrm{M} 2+$ $50 \%$ WC wt. coating (Figure 6(d)). However, these $\mathrm{M}_{6} \mathrm{C}$ carbide particles are coarser as compared to those found in $\mathrm{M} 2+$ $40 \%$ wt. WC coating (Figure 6(c)). Binder phase is found in the form of isolated particulates and, therefore, has no great effect on wear resistance of this coating. When comparing the wear resistances of deposited and heat-treated coatings, we note the wear rate increased by $\sim 20 \%$ in the latter case. We suggest that spalling of coarse carbides particles is not 
easy and the carbide framework is stable with respect to pure abrasive wear. However, the impact loading from abrasive particles will increase the wear rate of both carbide framework and more brittle matrix. Also the carbide crack network is formed in the deposited M2 + 50\% wt. WC coatings that will add to the process.

It follows from here that high wear resistance of the previously shown composite coatings is due to high content of the retained austenite. Such a conclusion is supported by numerous data found in the literature sources $[2,4,7,8]$. Another factor contributing to wear resistance is the multimodal size distribution of carbide particles. Apart from the retained austenite, there are another important factors that determine the wear resistance of HSS such as origin, quantity, character of distribution, and size of carbides [8-10]. It is known [11] that higher wear resistance of cast HSS as compared to wrought HSS is explained by the presence of hard eutectic carbide framework formed along $\gamma$-solid solution boundaries. The carbide framework was found to be more efficient for better wear resistance as compared to isolated coarse carbide particles under conditions of both abrasive and oxidative wear.

To prevent wear of relatively soft matrix grains, one of the possible solutions is to provide their reinforcement by fine carbides. The literature search devoted to WC-Co hard metal [12-14] shows that when successively reducing the carbide phase size from micro- to submicro- and then to nanosize for Co contents kept constant, we reduce the intercarbide binder layer and simultaneously increase the hardness. The wear resistance grows both in abrasive and sliding wear tests due to achieving smaller carbide grains and thinner intercarbide binder layers which serve to limit the selective binder wear and further spalling of carbide particles [12, 13].

In such a manner, $\mathrm{M} 2+20 \% \mathrm{WC}$ coating is most preferable for surfacing pinion-shaft journals since it shows good levels of wear resistance, hardness, no surface cracking, structural homogeneity of coating, and high amount of retained austenite which is one of the main factors to reduce the cyclic external stresses.

\section{Conclusions}

(1) It is established that WC particles interact with HSS M2 particles in the powder mixture during sintering the powder cakes and thus form $\mathrm{M}_{6} \mathrm{C}$ carbide. The WC content in a source powder mixture increased from 10 to $40 \%$ wt. corresponding to WC content 20 to $25 \%$ vol. in the cake.

(2) As shown, admixing 20 to $25 \%$ wt. WC into the surfacing mixture results in higher content of $\mathrm{M}_{6} \mathrm{C}$ carbide found in the forms of eutectic $5.9 \mu \mathrm{m}$ and fine $0.25 \mu \mathrm{m}$ carbides inside the grains (multimodal size distribution) in addition to VC $0.65 \mu \mathrm{m}$ carbides and higher amount of austenite- $88 \%$ vol.

(3) Increasing the WC content in the source powder mixture serves to reduce the abrasive wear rate irrespective of the abrasive particle type used in test (Figure 8). The most intensive wear resistance growth is observed for WC content $20 \%$ wt. coatings. This is related both to mechanical stress relief by straininduced $\gamma \rightarrow \alpha^{\prime}$ martensitic transformation during the wear test and effect of multimodal size distribution of carbides.

\section{Acknowledgment}

This work is carried out with financial support of State Task of NIR TPU no. 8.3664.2011.

\section{References}

[1] V. E. Panin, S. I. Belyuk, V. G. Durakov, G. A. Pribytkov, and N. G. Rempe, "Electron-beam deposition in a vacuum: the equipment, technology, properties of the coatings," Svarochnoe Proizvodstvo, no. 2, pp. 34-38, 2000.

[2] S. F. Gnyusov, A. A. Ignatov, and V. G. Durakov, "Structure and wear resistance of R6M5 steel based coatings," Technical Physics Letters, vol. 36, no. 8, pp. 745-748, 2010.

[3] T. V. Smyshlyaeva, "Assessment of the fracture energy in tripsteel during abrasive wear," Journal of Friction and Wear, vol. 22, no. 3, pp. 295-298, 2001.

[4] S. N. Kulkov and S. F. Gnyusov, Carbide Steels Based on Carbides of Titanium and Tungsten, Nauchno-Tekhnicheskoy Literatury, Tomsk, Russia, 2006.

[5] A. P. Gulyaev, Superplasticity of Steel, Metallurgiya, Moscow, Russia, 1982.

[6] S. G. Koop, Heat Treatment of HSS, Metallurgiya, Moscow, Russia, 1956.

[7] A. V. Makarov, L. G. Korshunov, I. Y. Malygina, and A. L. Osintseva, "Effect of laser quenching and subsequent heat treatment on the structure and wear resistance of a cemented steel 20KhN3A," Physics of Metals and Metallography, vol. 103, no. 5, pp. 507-518, 2007.

[8] E. Badisch and C. Mitterer, "Abrasive wear of high speed steels: influence of abrasive particles and primary carbides on wear resistance," Tribology International, vol. 36, no. 10, pp. 765770, 2003.

[9] E. Pippel, J. Woltersdorf, G. Pöckl, and G. Lichtenegger, "Microstructure and nanochemistry of carbide precipitates in high-speed steel S 6-5-2-5," Materials Characterization, vol. 43, no. 1 , pp. 41-55, 1999.

[10] S. F. Gnyusov, I. O. Khazanov, B. F. Sovetchenko et al., The Application of the Superplasticity Effect of Steels in the Tool Manufacturing, STB, Tomsk, Russia, 2008.

[11] A. S. Chaus and M. Hudáková, "Wear resistance of high-speed steels and cutting performance of tool related to structural factors," Wear, vol. 267, no. 5-8, pp. 1051-1055, 2009.

[12] K. Jia and T. E. Fischer, "Sliding wear of conventional and nanostructured cemented carbides," Wear, vol. 203-204, pp. 310-318, 1997.

[13] K. Jia and T. E. Fischer, "Abrasion resistance of nanostructured and conventional cemented carbides," Wear, vol. 200, no. 1-2, pp. 206-214, 1996.

[14] B. H. Kear and L. E. McCandlish, "Chemical processing and properties of nanostructured WC-Co materials," Nanostructured Materials, vol. 3, no. 1-6, pp. 19-30, 1993. 

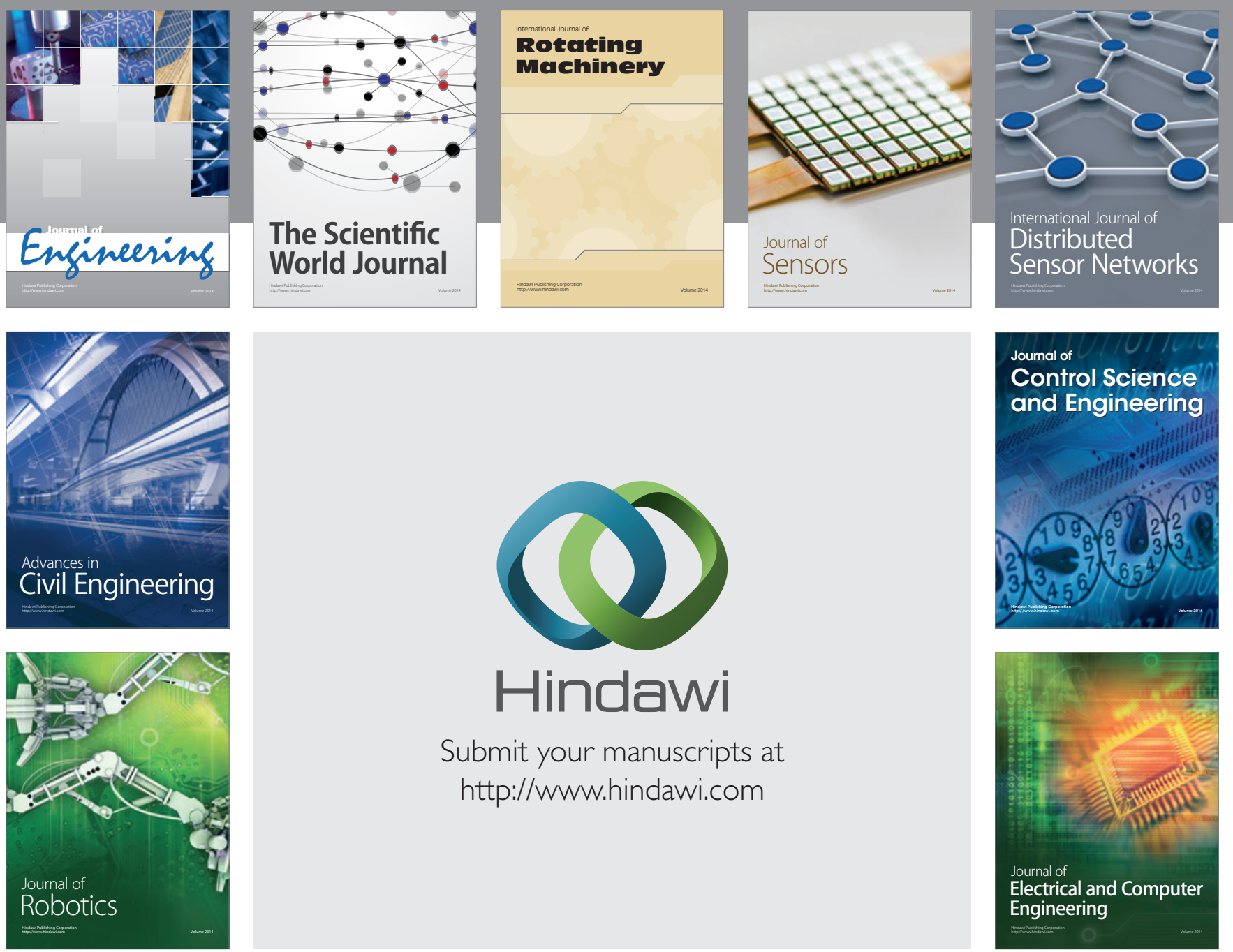

Submit your manuscripts at

http://www.hindawi.com
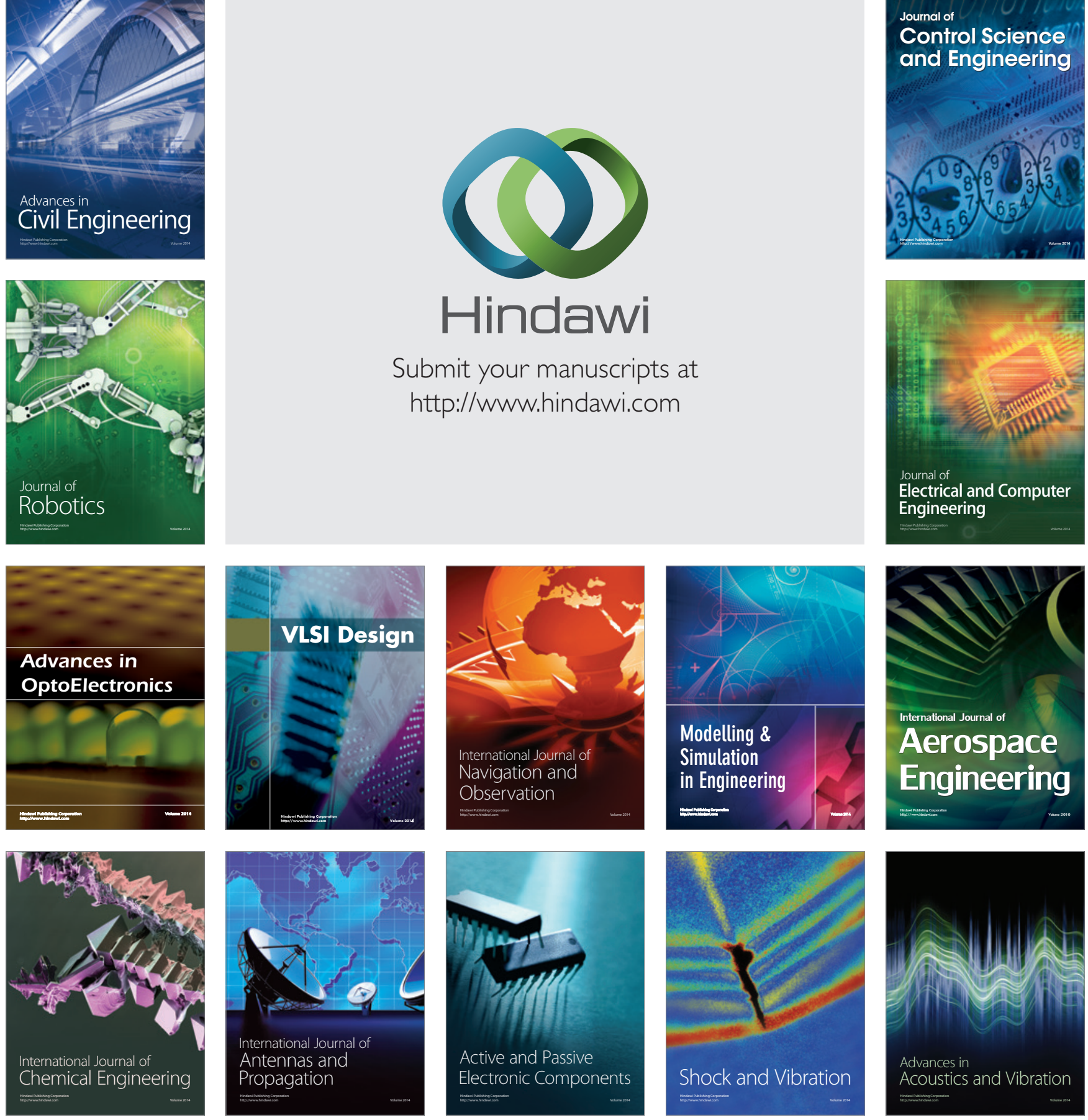